\title{
Sexual Behaviors and Pregnancies of in School and out of School Adolescents in Kavango region, Namibia
}

\author{
Article by Taimi Amakali-Nauiseb ${ }^{1}$, Honore K.Mitonga ${ }^{2}$ \\ ${ }^{1}$ University of Namibia University of Namibia \\ E-mail: tnauiseb@unam.na
}

\begin{abstract}
The objective of this study is to determine the sexual patterns among their school and out of school adolescents in Kavango region, Namibia and identify the association between the socio-demographic characteristics of the adolescents and their sexual behaviors.

A cross-sectional analytical study was conducted using mixed methods - quantitative and qualitative approaches among 350 school learners (grade 6 to grade 12) and 150 school dropout adolescents (aged 12 to 18 years). The stratified random sampling techniques were used in the selections of the circuit and the schools. Structured questionnaires were used in face-to-face interviews, and in depth interviews were conducted among the key informants (teachers). The following variables include the demographics (age, grade, parent marital status, and school drop-out status), sexual behavior (age at first sexual intercourse, number of sexual partners, abortion, and age at abortion), economic (employment, financial support).

Descriptive statistics was used to summarise the above-mentioned variables. Crosstabulations of demographic, sexual and economic variables were used to describe the relative frequencies.

The associations between different categorical variables were assessed using Chi-square test whilst the identification of different determining factors was analyzed with the epidemiological methods using odds ratios and/or estimated relative risks. The means, standard deviation and $95 \%$ confidence interval were computed. The differences between different variables or factors were considered to be statistically significant for p-values less than 0.05 .

The study found that early sexual debut, first sexual intercourse, number of sexual partners, relationship with sexual partners older than 5 years and dropping out of schoolwere associated with adolescent pregnancy in Kavango region.
\end{abstract}

Keywords: Adolescence, Adolescents, Reproductive health, Sexual behaviors, Sex education.

\section{Introduction}

Teenage pregnancies give an impression of being unwanted because they are never planned. According to (USAID, 2011) 91\% of teenage pregnancies in the Kavango region in Namibia were unwanted. The unplanned and unwanted pregnancies among teenage girls are often terminated by unsafe abortions which may have a long term negative effect on their social and emotional being. The Demographic Health Survey as reported in Ministry of health \& social service, (MOHSS) 2013 and USAID 2011study revealed that the teenage pregnancy rate in the Kavango Region was double the national average, standing at $34 \%$ among the 15 19 year old. The national average teenage pregnancy rate was $15 \%$ and $15.4 \%$ respectively; and three times the rates in some of the neighboring regions, such as Ohangwena, Omusati, and Oshana.

In Namibia, 2015the prevalence of adolescent pregnancy was 31.3\%; and as stated by Lillian P; Mumbango T, 2015, adolescent pregnancy was influenced by generation, region, highest educational level, socio-economic status and cultural factors. Therefore, intervention programs and policy initiatives should focus on youth, regions, everyone regardless of the socio-economic or culture. 
Although different regions of Namibia are affected, Kavango region in Northern Namibia is mostly affected by the problem of teenage pregnancy. According to a USAID report(USAID, 2011), the region has the highest rate of 34\% teenage pregnancy among 15 to 19 year olds.

With the commemoration of the World Population Day, the United Nations Population Fund (UNFPA,2013), released these statistics, which is celebrated on the 11 July every year. This year the theme was "Investing in Teenage Girls "When the statistics were compiled, there were 245431 adolescent girls population in Namibia aged between 15 and 19. 46000 adolescent fell pregnant, $66 \%$ of the population between 15 and 19, 39\% below the age of 15 .

As previously stated, the pregnancy rates are high in some regions, with $20 \%$ of teenagers in some rural areas becoming mothers earlier than their counterparts in urban areas. One of the reasons being is that rural teenage girls only have primary-level education, while girls in urban areas are better educated. Apart from the academic factor, the report also said some girls do not know how to avoid falling pregnant, while others feel shy or are ashamed to access contraceptives (Nomhle Kangootui, 2016; UNFPA, 2013).

The USAID report (USAID, 2011) on teenage pregnancy in Kavango region indicates that lack of access to family planning as a result of the traditional orientation of family planning in favor of older and married women by health care providers is partly responsible for teenage pregnancy in the region. Furthermore, the report indicated that while $98 \%$ of young people in Kavangowere informed about contraceptives, but only $8.7 \%$ of them use it. Condom use in the Kavango Region was very low at $36 \%$.

This article was extracted from the authors study "a model for reproductive health and pregnancy preventing strategies among adolescents in schools in Kavango region, Namibia" and thus cover the results related to the study to determine the sexual patterns among the in school and out of school adolescents in Kavango region, Namibia and identify the association between the socio-demographic characteristics of the adolescents and their sexual behaviors.

\section{Objectives}

The objective of this study is to determine the sexual patterns among the in school and out of school adolescents in Kavango region, Namibia and identify the association between the socio-demographic characteristics of the adolescents and their sexual behaviors.

Limitation of the study

The study focused only on public schools in Kavango region. Therefore, the outcomes of the study can only be recommended developing a model for adolescents within the public schools in Kavango regions. Consequently, the findings of the study need to be adjusted to the rest of the other schools in other regions in the country in order to be generalized. So, yes generalization of findings to the whole Namibian country will be applicable and will be done. Generalization of the study to Africa, the answer will be no because the model need to be adapted according to the countries culture and needs which need to be country specific. The model needs to be benchmark and due to constraints in time and resources implementation and evaluation of the model will not be completed now at the specific point in time.

\section{Delimitation of the study}

The study was carried out solely in Kavango region and not in any other regions of the country. The model needs to be benchmark and due to constraints in time and resources implementation and evaluation of the model will not be completed now at the specific point in time. 


\section{Methods}

\section{Study design}

A cross-sectional analytical study was conducted using mixed methods - quantitative and qualitative approaches among 350 school learners (grade 6 to grade 12) and 150 school dropout adolescents (aged 12 to 18 years). The stratified random sampling techniques were used in the selections of the circuit and the schools. Structured questionnaires were used in face-to-face interviews, and in depth interviews were conducted among the key informants (teachers). The following variables include the demographics (age, grade, parent marital status, and school drop-out status), sexual behavior (age at first sexual intercourse, number of sexual partners, abortion, and age at abortion), economic (employment, financial support).

\section{Study population}

The study population groups were in threefold, the school learners in primary or secondary school, the teachers at different schools and the adolescent's in the community who had dropped out of school.

\section{Target population}

The first target population were the school learners falling within the age group of between 12- 19 years, in public primary and as well secondary schools in Kavango region. The second target population were teachers at different schools teaching Life Science, Life Skills, Biology or Natural Science. The third target populations were the adolescent's in the communities who had dropped out and or never went to school and falls within the age group of between 12- 19 years.

\section{Sample size}

A sample size of 500 adolescents was determined using Epiinfo version 7 considering at least 95\% significance level.

Data collection: preparing the field,

For both the schools and the community: Prior telephonic arrangements were done with the school principals and councilors regarding the purposes of the visit, date and time for the visits to Kavango Region and to the specific schools.

\section{Data collection procedure at schools}

The researcher (Mrs. T.Nauiseb) reported at the principal's office whereby the researcher submitted all written proof of letters for permission as obtained from the different institutions.

The principal accompanied the researcher to the Laboratory classroom or Life Skills class where the data collection took place. At some schools, the teacher responsible for Life Science, Life Skills, Natural Science or Biology accompanied the researcher to the Laboratory classroom or to the Life Skills class where the data collection took place. At some instances the learners waited at the mentioned classrooms and at other schools learners were called for the data collection once the researcher turned up.

The researcher was provided in advance with the class list of the specific grades, and carried out simple random selection. At the Primary schools: all learners from the different grades 6-7 came to the one central classroom, which was the Life Skills class's room. At the Secondary schools: all learners from the different grades 8-12 came to the one central classroom, which was the Life Skills, Biology or the laboratory classroom.

After explaining the aims of the study and obtaining permission from the learners, the researcher distributed the questionnaires to each learner. The questionnaires were in English and consisted out of open ended close questions. The researcher utilized questionnaires with the learners to understand their take on the curriculum provided at schools. Questionnaires on the learners were used to collect data and an individual in-depth face-to-face interview was carried out with the teachers offering at school the abovementioned subjects. The teacher's indepth interview pointed out their challenges, experiences and shortcomings with the 
Texila International Journal of Public Health

Volume 4, Issue 4, Dec 2016

implementation of the curriculum. The data collected by the main researcher focused on reproductive issues, whether it is included and discussed comprehensively or partly in the abovementioned subjects.

The questionnaire's consisted out of five subsections which were as follows: demographic data; sexual and reproductive health characteristics potential risk factors, family planning and social background.

\section{Data collection procedure in the community}

The constituencies were visited on different days. The researcher (Mrs. T.Nauiseb) reported at the constituencies' office and the representative of the councilor was waiting as prior arranged.

\section{Conducting interviews}

After explaining the aims of the study and obtaining permission from the adolescents the researcher distributed the questionnaires to each learner. The researcher distributed the questionnaire to the learners and they responded to the questionnaires accordingly, the researcher was present for any possible questions or clarity. The learners took approximately 30-45 minutes to respond to the questionnaires.

\section{Data analysis}

Data were entered and analyzed using SPSS software version 23 was used in data analyses. Descriptive statistics was used to summarize the above-mentioned variables. Crosstabulations of demographic, sexual and economic variables were used to describe the relative frequencies. The associations between different categorical variables were assessed using Chi-square test whilst the identification of different determining factors was analyzed with the epidemiological methods using odds ratios and/or estimated relative risks. The means, standard deviation and $95 \%$ confidence interval were computed. The differences between different variables or factors were considered to be statistically significant for $\mathrm{p}$-values less than 0.05 .

\section{Results}

Table 1 provides the following: The mean age of respondents was 16 years, with a standard error of 0.107 and a standard deviation of 2.384 .

Age of first sexual intercourse was 15 years, with a standard error of 0.135 and a standard deviation of 2.086 .

Number of sexual partners in the past 12 months in total 224 out of 500 where having more than 1 sexual partner with a mean of 1.83 , with a standard error of 0.073 with a standard deviation of 1.099 .

The mean age at abortion was 16 years, which shows an association statistically significant ( $p$-value $=0.023<0.05$ ) between the ages of respondents.

$0.2 \%$ of adolescents who did perform abortion are age $12-15$ years; $2.4 \%$ of adolescents who did perform abortion are age 16-19 years.2.6\% of adolescent perform abortion which indicated that this is a public health concern and is statistically significant with a p-value of 0.023(Table 2).

In table 3, abortion with $95 \%$ confidence interval (CI) odd ratios (OR) varying between 0.017 to 1.019 for all age categories and the researcher found that the respondents aged 12 to 15 years perform abortion 0.198 times with $95 \%$ CI OR varying between 0.030 to 1.307; also the adolescents aged between 16 to 19 years perform 1.5 times abortion with a $95 \%$ CI OR varying between 1.270 to 1.792 . The results show that the adolescent have a minimum risk of performing abortion 0.017 times and a maximum risk of performing abortion of 1.019 times. These results are different from the specific ages 'categories.

Table 3, presented information association between grade, financial support and working and are statistically significant with a value $=0.021$. Financial support with $95 \%$ CI OR 
varying between 0.619 to 1.679 for married parents who are working and the researcher found that the adolescents are having 1.019 times chance of receiving financial support.

For those married parents not working the adolescents had 0.998 times chances of receiving pocket money with $95 \%$ CI OR varying between 0.938 to 1.061. The adolescents has a minimum chance 0.998 of receiving pocket money and a maximum chance of 1.019 times of receiving pocket money.

Pocket money with $95 \%$ CI OR for those working varying between 0.619 to 1.679 for married parents and the researcher found that the adolescents are 1.019 times chance of receiving pocket money. For those not working had 0.998 times chances of receiving pocket money with $95 \%$ confidence interval odd ratios varying between 0.938 to 1.061 . The adolescents has a minimum chance 0.998 of receiving pocket money and a maximum chance of 1.019 times of receiving pocket money (Table 3).

The social characteristics, was found having an association statistically significant between sex education and the grades of the participants ( $p$-value $=0.017<0.05$ ). Similarly, the risky behavior and the age were statistically significant $(\mathrm{p}$-value $=0.015<0.05)($ Table 4$)$.

Table 3 provide the adolescents study status who became pregnant with $95 \%$ CI OR varying between 0.786 to 2.415 ; the researcher found that those who became pregnant are 1.378times at risk of dropping out of school and those who didn't became pregnant are 0.942 times at risk of dropping out, with $95 \%$ CI OR varying between 0.856 to 1.036 .

The above results show that the adolescent who became pregnant have a minimum risk of dropping out of school 0.942 times and a maximum risk of dropping out of school 1.378 times.

\section{Discussion}

Adolescent pregnancy prevention research and programs predominantly focus on factors controlled by the adolescent girl. However, the most important factors linked to early pregnancy in this study are,age of sexual debut, number of sexual partners and the mean age of abortion, low family planning utilization, relationship with sexual partners older than 5 years and dropping out of school

The USAID reported that ignorance among the adolescent girls is also to blame for teenage pregnancy. The report indicates that while $98 \%$ of young people were informed about contraceptives, but only $8.7 \%$ of them use it. This claim is also substantiated by UNICEF's report, which indicates that adolescent girls in Namibia have low level of contraceptive use and, only above $61 \%$ of condom use(The United Nations Children's Fund (UNICEF), 2012).

Teenage pregnancy appears unwanted because it is unplanned. This is substantiated by the study on teenage pregnancy by the USAID (USAID, 2011)in Namibia the findings of which has proven that $91 \%$ of pregnancies among teenagers in Kavango region of Namibia were unwanted. Unplanned teenage pregnancy is often terminated by abortion, a negative experience that may have a lifelong emotional and social impact on her.

Teenagers in some rural areas becoming mothers earlier than their counterparts in urban areas. One of the reasons being is that rural teenage girls only have primary-level education, while girls in urban areas are better educated. Apart from the academic factor, the report also said some girls do not know how to avoid falling pregnant, while others feel shy or are ashamed to access contraceptives (Nomhle Kangootui, 2016; UNFPA, 2013).

Adolescent pregnancy was considered a private matter that only involved the pregnant adolescent and the immediate family members. This issue has now however become a public concern. An increasing awareness of social and economic consequences of adolescent pregnancy has led to a consensus among researchers and policy makers and the general public at large that adolescent pregnancy and childbearing is a serious social problem. It is linked to concerns such as the spread of HIV/ AIDS, non-marital births, sexual abuse and neglect, abortions, infant and maternal mortality, high rate of unemployment, school failure and dropouts, and loss of self-esteem and limited future career opportunities (Lillian P; Mumbango T, 2015). 
Texila International Journal of Public Health

Volume 4, Issue 4, Dec 2016

About 16 million girls aged 15 to 19 years and two million girls under the age of 15 give birth every year. Worldwide, one in five girls have given birth by the age of 18. In the poorest regions of the world, this figure rises to over one in three girls, almost all adolescent births about 95\% occur in low- and middle-income countries. Within countries, adolescent births are more likely to occur among poor, less educated and rural populations (WHO, 2014).

As indicated in the study by (Omar, K., Hasim, S., Muhammad, N. A., Jaffar, A., Hashim, S. M., \& Siraj, 2010), there were significant associations between adolescent pregnancy and low education level, low socioeconomic status, being raised by a single parent, not engaging in extracurricularschool activities, engaging in unsupervised activities with peers after school, and substance abuse being anemic, being unsure of the expected delivery date (Omar, K., Hasim, S., Muhammad, N. A., Jaffar, A., Hashim, S. M., \& Siraj, 2010).

\section{Conclusion}

The study found that early sexual debut, first sexual intercourse, number of sexual partners, relationship with sexual partners older than 5 years and dropping out of school were associated with adolescent pregnancy in Kavango region.

\section{Figures and tables}




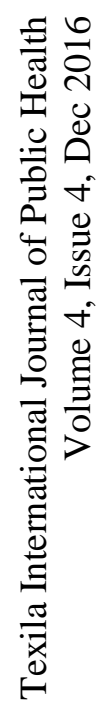

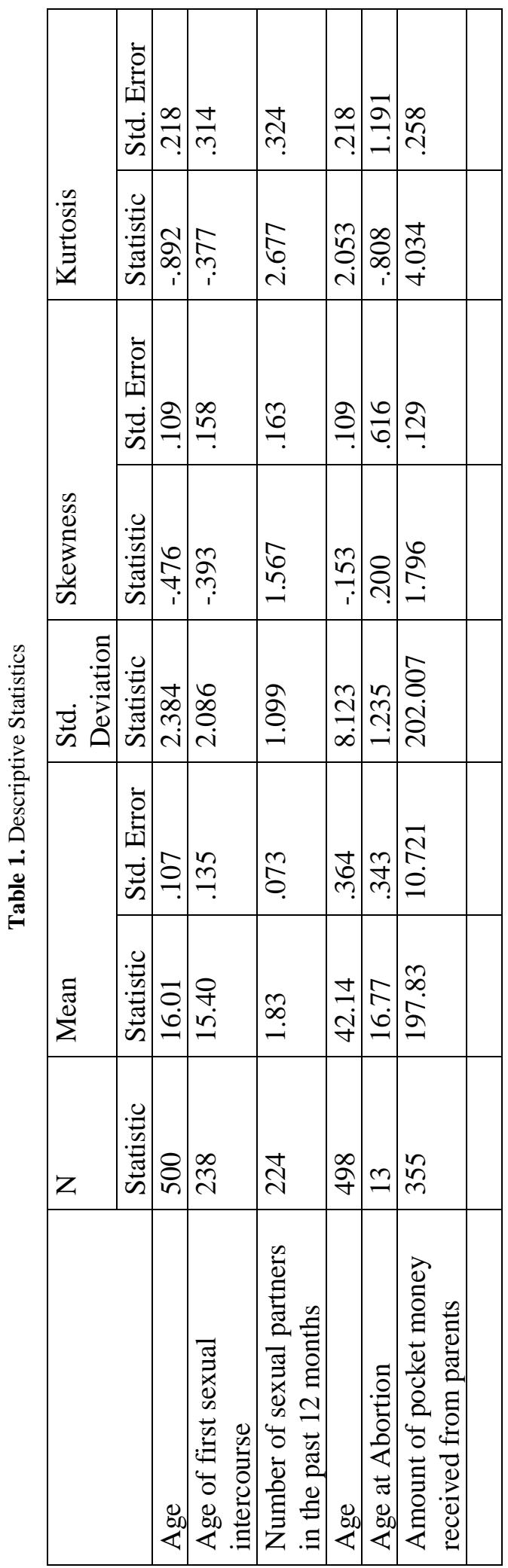


Texila International Journal of Public Health

Volume 4, Issue 4, Dec 2016

Table 2. Demographic Characteristics-Association between abortion and age-category

\begin{tabular}{|c|c|c|c|c|c|c|}
\hline & \multicolumn{2}{|c|}{ Age-Category } & \multirow[t]{2}{*}{ Total } & \\
\hline & & & $12-15$ & $16-19$ & & P-value \\
\hline \multirow[t]{4}{*}{ Abortion } & Yes & Count & 1 & 12 & 13 & \multirow{6}{*}{0.023} \\
\hline & & $\begin{array}{l}\text { \% of } \\
\text { Total }\end{array}$ & $0.2 \%$ & $2.4 \%$ & $2.6 \%$ & \\
\hline & No & Count & 189 & 298 & 487 & \\
\hline & & $\begin{array}{l}\text { \% of } \\
\text { Total }\end{array}$ & $37.8 \%$ & $59.6 \%$ & $97.4 \%$ & \\
\hline \multirow{2}{*}{\multicolumn{2}{|c|}{ Total }} & Count & 190 & 310 & 500 & \\
\hline & & $\begin{array}{l}\text { \% of } \\
\text { Total }\end{array}$ & $38.0 \%$ & $62.0 \%$ & $100.0 \%$ & \\
\hline
\end{tabular}

* P-value statistically significant at the level of significant 0.05

Table 3. Risk Estimate

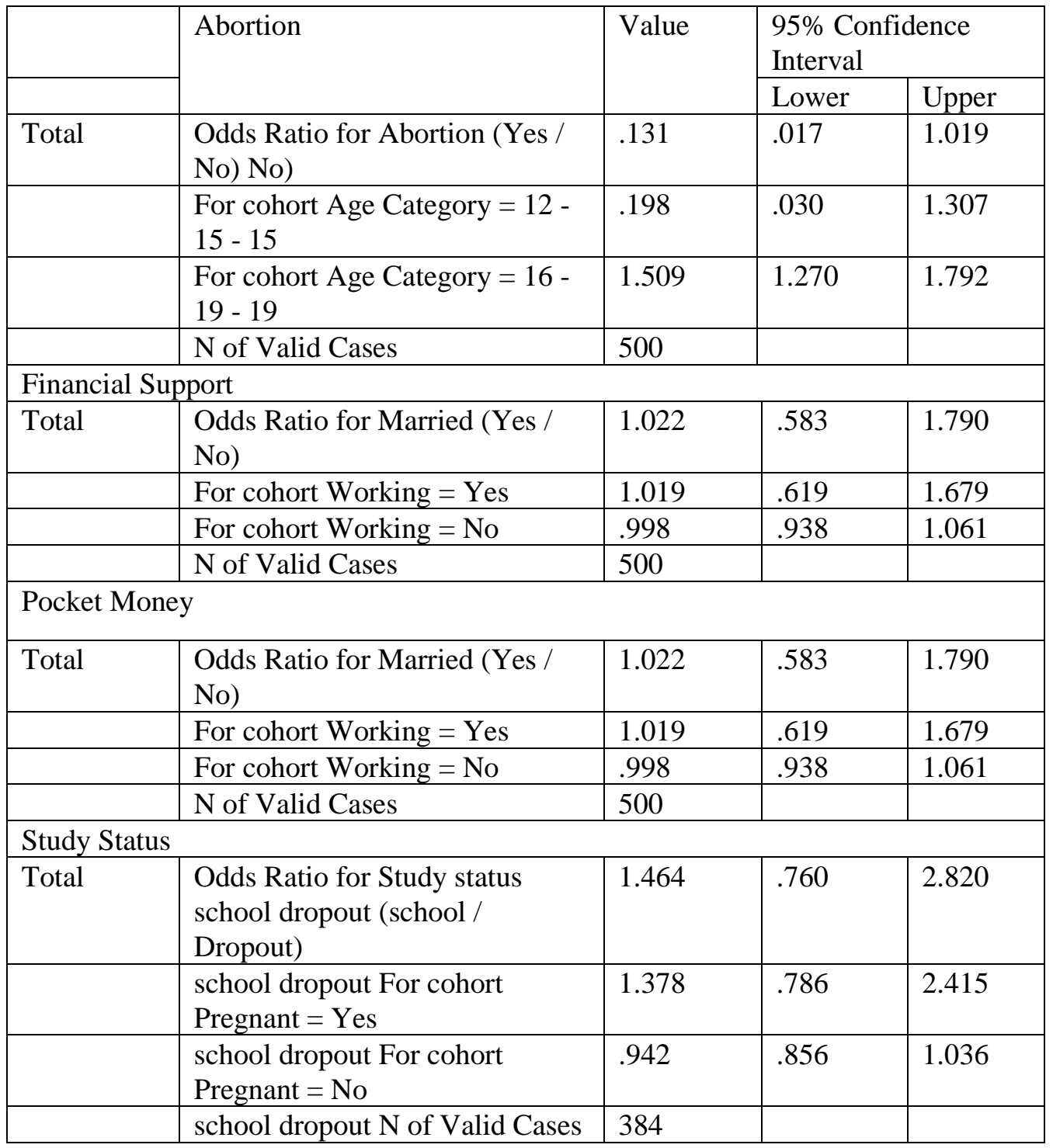


Texila International Journal of Public Health Volume 4, Issue 4, Dec 2016

Table 4. Social characteristics -Association between sex education and grades

\begin{tabular}{|c|c|c|c|c|c|c|}
\hline & \multicolumn{3}{|c|}{ Sex education } & \multirow[t]{2}{*}{ Total } & \multirow[t]{2}{*}{ P-value } \\
\hline & & \multirow{2}{*}{$\begin{array}{l}\text { Yes } \\
26 \\
\end{array}$} & \multirow{2}{*}{$\begin{aligned} \text { No } \\
14 \\
\end{aligned}$} & \multirow{2}{*}{$\begin{array}{r}\text { Not } \\
\text { sure } \\
12 \\
\end{array}$} & & \\
\hline \multirow{7}{*}{$\begin{array}{l}\text { Grad } \\
\text { es }\end{array}$} & Grade 6 & & & & 52 & \multirow{8}{*}{0.017} \\
\hline & Grade 7 & 37 & 12 & 10 & 59 & \\
\hline & Grade 8 & 56 & 8 & 4 & 68 & \\
\hline & Grade 9 & 48 & 11 & 2 & 61 & \\
\hline & $\begin{array}{l}\text { Grade } \\
10 \\
\end{array}$ & 40 & 20 & 1 & 61 & \\
\hline & $\begin{array}{l}\text { Grade } \\
11\end{array}$ & 58 & 32 & 3 & 93 & \\
\hline & $\begin{array}{l}\text { Grade } \\
12\end{array}$ & 80 & 23 & 3 & 106 & \\
\hline \multicolumn{2}{|l|}{ Total } & 345 & 120 & 35 & 500 & \\
\hline \multicolumn{5}{|c|}{ Risky Behavior } & & \multirow{10}{*}{0.015} \\
\hline \multirow[t]{8}{*}{ Age } & 12 & 24 & 15 & 11 & 50 & \\
\hline & 13 & 29 & 25 & 6 & 60 & \\
\hline & 14 & 32 & 7 & 2 & 41 & \\
\hline & 15 & 40 & 8 & 5 & 53 & \\
\hline & 16 & 50 & 14 & 7 & 71 & \\
\hline & 17 & 41 & 16 & 0 & 57 & \\
\hline & 18 & 71 & 19 & 9 & 99 & \\
\hline & 19 & 64 & 14 & 5 & 83 & \\
\hline \multicolumn{2}{|l|}{ Total } & 349 & 113 & 38 & 500 & \\
\hline
\end{tabular}

* P-value statistically significant at the level of significant 0.05

Table 5. Sexual and reproductive health characteristics -Association between sexual partner in 12months, partner older and partner HIV status

\begin{tabular}{|c|c|c|c|c|c|c|c|c|}
\hline \multicolumn{3}{|l|}{ Older } & \multicolumn{4}{|c|}{ HIV Part. } & \multirow[t]{2}{*}{ Total } & P-value \\
\hline \multirow{3}{*}{ Yes } & \multirow{2}{*}{$\begin{array}{l}\text { Sexual } \\
\text { Partners } \\
\text { 12months }\end{array}$} & Yes & $\begin{array}{l}\begin{array}{l}\text { Negat } \\
\text { ive }\end{array} \\
15 \\
\end{array}$ & $\begin{array}{l}\text { Positive } \\
5\end{array}$ & $\begin{array}{l}\text { Unknown } \\
14\end{array}$ & $\begin{array}{l}\text { Not } \\
\text { applicable }\end{array}$ & & \multirow{9}{*}{0.007} \\
\hline & & No & 18 & 2 & 13 & & 33 & \\
\hline & \multicolumn{2}{|l|}{ Total } & 33 & 7 & 27 & & 67 & \\
\hline \multirow[t]{3}{*}{ No } & \multirow{2}{*}{$\begin{array}{l}\text { Sexual } \\
\text { Partners } \\
\text { 12months }\end{array}$} & Yes & 63 & 13 & 96 & 0 & 172 & \\
\hline & & No & 135 & 14 & 110 & 2 & 261 & \\
\hline & \multicolumn{2}{|l|}{ Total } & 198 & 27 & 206 & 2 & 433 & \\
\hline \multirow[t]{3}{*}{ Total } & \multirow{2}{*}{$\begin{array}{l}\text { Sexual } \\
\text { Partners } \\
\text { 12months }\end{array}$} & Yes & 78 & 18 & 110 & 0 & 206 & \\
\hline & & No & 153 & 16 & 123 & 2 & 294 & \\
\hline & \multicolumn{2}{|l|}{ Total } & 231 & 34 & 233 & 2 & 500 & \\
\hline
\end{tabular}

* P-value statistically significant at the level of significant 0.05 
Texila International Journal of Public Health

Volume 4, Issue 4, Dec 2016

\section{References}

[1]. Lillian P; Mumbango T. (2015). Statistical Modeling of Adolescent Pregnancy in Namibia. J Nurs Care, 4, 262. doi:10.4172/2167-1168.1000262

[2]. Ministry of Health \& Social Services (MoHSS). (2013). Namibia Demographic Health Survey 2013.

[3]. Nomhle Kangootui. (2016). Pregnancy statistics in Namibia. Namibian Newspaper, p. 14 July 2016.

[4]. Omar, K., Hasim, S., Muhammad, N. A., Jaffar, A., Hashim, S. M., \& Siraj, H. H. (2010). Adolescent Pregnancy Outcomes and Risk factors in Malaysia. International Federation of Gynecology and Obstetrics, 111(3), 220-223. doi:http://doi.org/10.1016/j.ijgo.2010.06.023

[5]. The United Nations Children's Fund (UNICEF). (2012). Progress for Children: A Report Card on Adolescents.

[6]. UNFPA. (2013). World Population Day the United Nations Population Fund.

[7]. USAID. (2011). Teenage Pregnancy in Kavango Region. Contributing Factors and Program Recommendations.

[8]. WHO. (2014). Adolescent Pregnancy Fact Sheet. Geneva, Switzerland. 